\title{
Enfermedades hepáticas y embarazo
}

\section{Liver diseases and pregnancy}

\author{
Luis Guillermo Toro, Elizabeth María Correa², Luisa Fernanda Calle², Adriana 0campo³, Sandra María Vélez
}

\footnotetext{
1 Hepatólogo clínico y de trasplantes. Director Unidad Funcional de Trasplantes y Enfermedades Digestivas de los Hospitales de San Vicente Fundación. Magister en Economía de la Salud. MedellínRionegro, Antioquia, Colombia.

2 Hepatóloga clínica y de trasplantes, Hospitales de San Vicente Fundación, Medellín-Rionegro, Antioquia, Colombia.

3 Médico general, estudiante de maestría en Epidemiología, Hospital San Vicente Fundación, Rionegro, Antioquia, Colombia.

${ }^{4}$ Especialista en Ginecología y Obstetricia, Jefe departamento de Obstetricia y Ginecología, Universidad de Antioquia. Medellín, Antioquia, Colombia.

*Correspondencia: Luis Guillermo Toro, luis.toro@sanvicentefundacion.com

Fecha recibido: $\quad 18 / 02 / 19$

Fecha aceptado: $13 / 05 / 19$
}

\begin{abstract}
Resumen
La prevalencia de las enfermedades hepáticas en el embarazo no es despreciable, ya que estas se presentan en 3\%-5\% de todas las gestaciones. Entre las múltiples causas se encuentran cambios fisiológicos del embarazo; enfermedad hepática preexistente, siendo las más comunes las enfermedades colestásicas (colangitis biliar primaria y colangitis esclerosante primaria), hepatitis autoinmune, enfermedad de Wilson, hepatitis virales crónicas, cirrosis establecida de cualquier etiología y paciente con historia de trasplante hepático; enfermedad hepática adquirida durante el embarazo, siendo las principales las hepatitis virales, la toxicidad inducida por medicamentos y la hepatolitiasis; hepatopatía relacionada con el embarazo, en la cual se encuentran 5 entidades principales: hiperémesis gravídica, colestasis intrahepática del embarazo, preeclampsia, síndrome HELLP e hígado graso del embarazo.

La severidad de estas entidades tiene una amplia gama de presentaciones, desde la paciente que es completamente asintomática, hasta la falla hepática aguda e incluso la muerte. La gravedad del cuadro se asocia con una morbilidad y mortalidad significativas tanto para la madre como para el feto, lo cual hace que una evaluación rápida, diagnóstico certero y manejo apropiado por un equipo multidisciplinario (incluida obstetricia de alto riesgo, hepatología, gastroenterología y radiología intervencionista), en un servicio que tenga la posibilidad de ofrecer trasplante hepático, sean fundamentales para obtener buenos desenlaces.
\end{abstract}

\section{Palabras clave}

Embarazo, hiperémesis gravídica, colestasis gestacional, HELLP, preeclampsia, virus de la hepatitis $\mathrm{B}$, cirrosis, trasplante hepático.

\begin{abstract}
Liver diseases develop in $3 \%$ to $5 \%$ of all gestations. Among the causes are: 1 . Physiological changes of pregnancy. 2. Pre-existing liver diseases and conditions. The most common are cholestatic diseases such as primary biliary cholangitis and primary sclerosing cholangitis. Others include autoimmune hepatitis, Wilson's disease, chronic viral hepatitis, cirrhosis of any etiology and histories of liver transplantation. 3. Liver disease acquired during pregnancy, especially viral hepatitis, drug-induced toxicity and hepatolithiasis. 4. Pregnancyrelated liver diseases including hyperemesis gravidarum, intrahepatic cholestasis of pregnancy, preeclampsia, HELLP syndrome and fatty liver of pregnancy.

Severity ranges from absence of symptoms to acute liver failure and even death. Severe cases have significant morbidity and mortality for both mother and fetus. These cases require rapid evaluation, accurate diagnosis and appropriate management by a multidisciplinary team including high-risk obstetrics, hepatology, gastroenterology and interventional radiology. Availability of liver transplantation is also important for obtaining good outcomes.
\end{abstract}

\section{Keywords}

Pregnancy, hyperemesis gravidarum, gestational cholestasis, HELLP, preeclampsia, hepatitis B virus, cirrhosis, liver transplantation. 


\section{INTRODUCCIÓN}

Todas las mujeres, independiente de la edad, están en riesgo de sufrir algún tipo de enfermedad hepática, sea aguda o crónica, siendo de vital importancia un óptimo manejo cuando estas patologías afectan a las mujeres en embarazo, no solo por los efectos adversos propiamente dichos, sino también por los desenlaces maternos y fetales. La presencia de enfermedades hepáticas agudas o crónicas en mujeres, embarazadas y no, hace que se requieran cambios en el cuidado ginecológico, la anticoncepción, el planeamiento del embarazo, la exploración de cáncer de cérvix, vacuna contra el papiloma y terapia de remplazo hormonal posmenopáusica.

Las mujeres con trasplantes hepáticos requieren un cuidado ginecológico que se adapte a su estado de inmunosupresión, para lograr no solo el bienestar de la madre, sino también la viabilidad del feto.

\section{CAMBIOS FISIOLÓGICOS NORMALES EN EL EMBARAZO}

En un embarazo normal pueden ocurrir muchos cambios fisiológicos y hormonales en el cuerpo de la mujer gestante, algunos de los cuales pueden parecerse a los que ocurren en pacientes con enfermedad del hígado. Hay aumento de la frecuencia cardíaca materna, del gasto cardíaco, del volumen circulatorio y una reducción en la resistencia vascular periférica. Estos cambios pueden también ser comunes en pacientes con enfermedad hepática crónica descompensada. En el examen físico de la mujer gestante, algunas pueden mostrar eritema palmar y la presencia de nevus arácnidos hasta en un $70 \%$. El flujo sanguíneo del hígado permanece constante durante el embarazo y el hígado no es palpable porque es desplazado un poco hacia arriba en la cavidad torácica, debido al crecimiento del útero; la motilidad de la vesícula biliar disminuye, lo que resulta en un incremento del riesgo del desarrollo de cálculos biliares (1).

Los índices bioquímicos y hematológicos tomados durante la gestación deben ser interpretados a la luz de los rangos normales para la mujer gestante. La fosfatasa alcalina aumenta en el tercer trimestre, al ser producida por la placenta y por desarrollo del hueso fetal, la alfafetoproteína aumenta en el embarazo y es producida por el hígado fetal. Los niveles de urea, hemoglobina y tiempo de protrombina permanecen sin cambios o ligeramente reducidos debido a la hemodilución. Las elevaciones en las transaminasas, bilirrubinas o tiempo de protrombina son anormales e indican estados patológicos, los cuales requieren estudios adecuados.

El embarazo es un estado procoagulante y los factores de coagulación (I, II, V, VII, X, XII) y el fibrinógeno están aumentados. Pueden evidenciarse pequeñas varices esofágicas hasta en un 50\% de las mujeres gestantes en el segundo y tercer trimestre, esto debido a la compresión que hace el útero sobre la vena cava inferior y a una reducción en el retorno venoso. Es poco frecuente que se indique la realización de una biopsia hepática, pero si ella se efectúa, los riesgos durante la gestación son muy similares a los de aquellas mujeres no gestantes $(2,3)$. La disfunción del hígado en el embarazo puede deberse a enfermedades hepáticas asociadas con el embarazo, exacerbación de enfermedades hepáticas preexistentes o condiciones no relacionadas con la gestación (Tabla $\mathbf{1}$ ).

Tabla 1. Enfermedades hepáticas en el embarazo (4)

Enfermedades hepáticas relacionadas con el embarazo

\begin{tabular}{l} 
Hiperémesis gravídica \\
Colestasis intrahepática gestacional \\
Enfermedades del hígado relacionadas con la hipertensión \\
Preeclampsia/eclampsia \\
Síndrome HELLP \\
Hematoma subcapsular y ruptura hepática \\
Hígado graso agudo del embarazo \\
\hline Enfermedades hepáticas no relacionadas con el embarazo \\
\hline Enfermedades hepáticas preexistentes \\
Viral \\
Autoinmunes (hepatitis autoinmune, colangitis biliar primaria, \\
colangitis esclerosante primaria) \\
Metabólicas (enfermedad de Wilson, hemocromatosis) \\
Cirrosis e hipertensión portal \\
Postrasplante hepático \\
Otras enfermedades hepáticas preexistentes \\
Coincidentes con el embarazo \\
Autoinmune \\
Viral \\
Vascular \\
Hepatotoxicidad inducida por medicamentos \\
\hline Enfermedades que pueden ser exacerbadas durante el embarazo \\
\hline Síndrome de Budd-Chari \\
Adenoma hepático \\
Enfermedad poliquística \\
\hline
\end{tabular}

\section{HIPERÉMESIS GRAVÍDICA}

La hiperémesis gravídica (HG) se presenta en el 0,3\% al 3\% de los embarazos $(5,6)$. Esta se define como la presencia de vómito persistente no relacionado con otras causas, que lleva a deshidratación, cetosis y pérdida de más de 5\% del peso preconcepcional (5). Usualmente inicia muy temprano en la gestación y se resuelve a la semana $20(2,7)$. El diagnóstico es básicamente de exclusión, la causa exacta no es clara y se han planteado múltiples teorías genéticas, psiquiátricas, psicologías, culturales y hormonales, alteraciones de la motilidad gástrica y cambios en el sistema ner- 
vioso autónomo e incluso se ha postulado su relación con la infección por Helicobacter pylori $(5,6,8,9)$.

Existe una correlación entre el pico de gonadotropina coriónica humana (HCG) en el primer trimestre y la severidad de la hiperémesis gravídica. El hipertiroidismo se presenta en el $60 \%$ de las pacientes con HG $(1,2,8,9)$. La HCG activa los receptores de la hormona estimulante de tiroides (TSH), lo que lleva a supresión de esta y aumento de los niveles de tiroxina $(2,5)$.

Los factores de riesgo claramente identificados son embarazos molares y gemelares, enfermedad trofoblástica, historia previa de HG y anormalidades fetales, además del incremento en el índice de masa corporal, enfermedades psiquiátricas y diabetes $(2,7,8)$. La alteración en la bioquímica hepática se presenta en el 50\%-60\% de las pacientes con HG hospitalizadas y se caracteriza por una ligera elevación de las transaminasas. La ictericia y la disfunción sintética son poco comunes (2, 7). Asimismo, las pacientes pueden presentar disfunción renal y trastornos electrolíticos, tales como hiponatremia, hipocalemia y alcalosis hipoclorémica $(2,6)$. En casos severos, la deshidratación puede llevar a hipotensión ortostática, taquicardia y letargia. El vómito puede llevar a sangrados por laceraciones esofágicas y a deficiencia de vitaminas que, en muy raros casos, puede producir alteraciones neurológicas $(5,6)$. No se ha demostrado claramente en la literatura relación de la HG con morbilidad fetal, algunos estudios han reportado mayores tasas de bajo peso al nacer y partos pretérmino $(6,9)$.

El manejo de la HG se basa en medidas de soporte, hasta que los síntomas se resuelvan con la progresión de la edad gestacional $(2,6,10)$. Se indica la rehidratación intravenosa, corrección de trastornos electrolíticos y la reposición de tiamina para prevenir la encefalopatía de Wernicke, sobre todo en pacientes que van a recibir soluciones dextrosadas $(6,9)$. La vitamina $\mathrm{B}_{6}$, para control de las náuseas y el vómito, es considerada la terapia de primera línea $(2,5)$. Los antieméticos son considerados de segunda línea (2). En pacientes refractarios, tanto los esteroides sistémicos como el ondansetrón pueden considerarse, teniendo en cuenta su perfil de seguridad $(2,5)$. Pacientes que no pueden mantener el peso y no responden a los antieméticos requieren nutrición enteral avanzada e incluso nutrición parenteral total $(5,6,9)$.

Las alteraciones bioquímicas usualmente mejoran con la resolución del vómito y no dejan secuelas hepáticas permanentes. En caso de que las pruebas hepáticas no se normalicen con la resolución del vómito se deberá sospechar otras posibles causas (8).

\section{COLESTASIS INTRAHEPÁTICA DEL EMBARAZO}

La colestasis intrahepática del embarazo (ICP) afecta 1 de cada 140 embarazos en el Reino Unido. Es más común en mujeres con historia familiar o personal de ICP, historia de prurito con los anticonceptivos orales, cálculos en la vesícula o embarazos múltiples. Algunos estudios sugieren una alta prevalencia en pacientes con infección por el virus de la hepatitis $\mathrm{C}$ e hígado graso no alcohólico $(4,11,12)$. Generalmente se presenta en el 3 trimestre de la gestación, pero se han reportados casos tan tempranos como desde la semana 8 de embarazo. Se caracteriza por prurito, alteración en las pruebas de función hepática y aumento de los niveles de ácidos biliares séricos. Los síntomas son coluria, acolia, anorexia, fatiga, dolor epigástrico y esteatorrea debido a malabsorción grasa; las transaminasas usualmente están elevadas $(4,8,11,12)$.

El prurito es de predominio nocturno y afecta usualmente palmas y plantas. Puede llegar a ser severo, característicamente mejora luego de las 48 horas del parto. La elevación de las bilirrubinas es poco común, pero, cuando se presenta, aumentan 2 a 4 semanas luego de la aparición del prurito. Su aumento se puede dar antes o después de la elevación de los ácidos biliares. Se ha encontrado que la ALT es un marcador más sensible en ICP, ya que hay una elevación entre 2 y 10 veces mayor que la AST. La ictericia clínica es rara, se puede presentar en el 10\%-15\% de las mujeres embarazadas con ICP. Si esto ocurre generalmente es leve, con niveles de bilirrubina que no exceden los 100 $\mu \mathrm{mol} / \mathrm{L}$ o $5,85 \mathrm{mg} / \mathrm{dL}$, siendo principalmente hiperbilirrubinemia a expensas de la directa. La malabsorción de vitamina K aumenta el riesgo de hemorragia posparto (4).

La ICP es una condición benigna para la madre, pero cuando se desarrolla la enfermedad severa (ácidos biliares $>40 \mathrm{mmol} / \mathrm{L}$ ) se ha encontrado aumento del riesgo de desenlaces adversos, incluido parto pretérmino, sufrimiento fetal, líquido amniótico teñido de meconio, requerimiento de UCI neonatal por largo tiempo y mortinatos $(12,13)$.

La patogénesis es desconocida, pero está relacionada con un transporte biliar anormal a través de la membrana canalicular. La proteína de resistencia a múltiples medicamentos 3 (MDR3) es el principal transportador de fosfolípidos. La mutación en este gen lleva a una pérdida en la función, lo que aumenta los ácidos biliares séricos. La mutación MDR3 está localizada en el cromosoma 7q21.1 y se ha identificado en el $15 \%$ de las causas de ICP. Un transporte anormal placentario de ácidos biliares de la circulación fetal a la materna aumenta los ácidos biliares maternos, además, un sistema de transporte fetal inmaduro puede contribuir a un incremento en los niveles de ácidos biliares en el feto (4).

El diagnóstico de ICP es de descarte y se deben buscar otras causas de colestasis (13). Los ácidos biliares séricos son los exámenes más sensibles y específicos para el diagnóstico y monitorización de esta condición. Por lo regular, la biopsia hepática no es necesaria para su diagnóstico, si se realiza, los hallazgos predominan en la zona 3, estos son la colestasis 
centrilobular sin inflamación, así como la presencia de tapones biliares en hepatocitos y canalículos (4).

El tratamiento es el ácido ursodesoxicólico (UDCA) (10$15 \mathrm{mg} / \mathrm{kg}$ ). Este es el único medicamento que ha demostrado beneficios en los síntomas maternos y la bioquímica hepática, además de posibles efectos benéficos en los desenlaces perinatales. Algunos estudios han demostrado que aumenta la expresión de transportadores placentarios de ácidos biliares, lo que mejora la transferencia de los mismos. Es antiapoptótico y aumenta la excreción de pruritógenos, como el sulfato de progesterona. Los estudios sugieren que su uso tiene un impacto positivo en los partos prematuros, en el ingreso de los neonatos a la UCI, en el daño placentario y en el desarrollo de arritmias fetales $(2,4,12,14)$. Otros medicamentos, que incluyen colestiramina, S-adenosina L-metionina y dexametasona, son menos efectivos que el UDCA en reducir el prurito y mejorar la función hepática; incluso se ha encontrado que la colestiramina puede exacerbar el déficit de vitamina $K(8,12,14)$.

La rifampicina puede ser útil como tratamiento adyuvante al UDCA en mujeres con enfermedad severa o refractaria. En un tercio de las pacientes mejora los síntomas y la bioquímica en pacientes que no respondieron al UDCA, pero solo se debe usar si las transaminasas no están demasiado elevadas $(2,12)$. Se ha encontrado una asociación entre los mortinatos en ICP y la semana 38 de embarazo, por lo cual, muchos centros han optado por terminar el embarazo antes de ese tiempo.

Los síntomas y las alteraciones en el perfil hepático desaparecen luego del parto, sin embargo, algunos pueden presentar un curso más prolongado. Se deben realizar niveles de ácidos biliares y enzimas hepáticas de 6 a 8 semanas luego del parto; si después de este tiempo las enzimas no mejoran se deben buscar otras causas de colestasis. Existe un alto riesgo de recurrencia de ICP en los embarazos posteriores, incluso, algunas mujeres pueden presentar colestasis con los ciclos menstruales o con el uso de anticonceptivos orales, por lo cual deben evitar medicamentos que contengan estrógenos $(12,14)$. Hay evidencia de que aquellas mujeres que presentaron ICP tienen un alto riesgo de desarrollar enfermedad hepatobiliar o síndrome metabólico en el transcurso de su vida $(4,12)$.

\section{SÍNDROME DE HELLP}

La preeclampsia es la causa más común de alteraciones en la función hepática durante el embarazo. Esta se caracteriza por la presencia de hipertensión y proteinuria luego de las 20 semanas de embarazo. La presencia de dolor en el cuadrante superior derecho del abdomen es sugestiva de compromiso hepático y requiere vigilancia estrecha (13).
El síndrome de HELLP se caracteriza por la presencia de hemolisis microangiopática, elevación de las enzimas hepáticas y disminución en las plaquetas. Este ocurre en el $0,2 \%-0,8 \%$ de los embarazos y en el 70\%-80\% de los casos coexiste con preeclampsia. La mayoría de los casos ocurren en el tercer trimestre del embarazo. La mortalidad perinatal es del 6\%-70\%, la cual es secundaria a la prematurez de los bebes y a complicaciones maternas. Algunos de los factores de riesgo son la edad avanzada de la materna, nulíparidad y la multiparidad $(4,10)$.

Se cree que la patogénesis del HELLP es debido a una alteración en la activación de las plaquetas, aumento en las citocinas proinflamatorias y vasoespasmo segmentario con daño del endotelio vascular (4). La mayoría de los pacientes se presenta con dolor abdominal en el cuadrante superior derecho, náuseas, vómito, malestar general, cefalea, cambios visuales, edemas periféricos y aumento de peso. La hipertensión y la proteinuria ocurren en el $80 \%$ de los casos. La ictericia es rara y solo se presenta en el 5\% de las pacientes, así como síntomas asociados con la trombocitopenia, como sangrado por mucosas, hematuria, petequias y hematomas; menos común son la falla renal (con aumento de ácido úrico), la diabetes insípida y el síndrome antifosfolípido (SAF) $(4,11,15)$.

Debido a la hemolisis, los pacientes cursan con niveles elevados de bilirrubinas, principalmente indirecta, aumento de la deshidrogenasa láctica (LDH). Además, hay una elevación moderada de las enzimas hepáticas ALT y AST. En estadios iniciales, el tiempo de protrombina (TP) y el tiempo de tromboplastina parcial (ТTP) son normales. En estadios tardíos se puede presentar una coagulación intravascular diseminada (CID), con niveles elevados de productos de la degradación de la fibrina, dímero $\mathrm{D}$ y complejo trombina-antitrombina (4). En el Task Force del Colegio Americano de Obstetricia y Ginecología sobre hipertensión en el embarazo se estandarizaron los criterios diagnósticos para el síndrome de HELLP (Tabla 2) (15).

Tabla 2. Criterios recomendados para el diagnóstico de síndrome de HELLP (15)

\footnotetext{
Hemolisis (al menos 2 de los siguientes):

Extendido de sangre periférica (esquistocitos, equinocitos)

Bilirrubina sérica $>1,2 \mathrm{mg} / \mathrm{dL}$ (predominio indirecto)

Haptoglobina sérica baja

Anemia severa no relacionada con pérdidas sanguíneas

Elevación de enzimas hepáticas

AST o ALT $\geq 2$, límite superior normal

$\mathrm{LDH} \geq 2$, límite superior normal

Trombocitopenia (plaquetas $<100000 / \mathrm{mm}^{3}$ )
} 
Se estima que 1 de cada 1000 mujeres embarazadas desarrolla HELLP, de estas, el 2\%-3\% presenta complicaciones hepáticas, que incluyen falla hepática que requiere trasplante hepático. La ruptura hepática en una rara complicación, la cual amenaza la vida de las que la desarrollan. Generalmente está precedida por una hemorragia intraparenquimatosa que progresa a un hematoma subscapular contenido en el lóbulo hepático derecho. Los niveles de ácido úrico $>464 \mu \mathrm{mol} / \mathrm{L}(7,8 \mathrm{mg} / \mathrm{dL})$ se asocian con mayor morbimortalidad materna y fetal $(4,8)$.

Una vez el HELLP se desarrolla, el único tratamiento es el nacimiento del bebe. Si la edad gestacional esta entre la $24 \mathrm{y}$ 34 semana se requieren esteroides para la maduración pulmonar. El parto debe ser 24 horas luego de la aplicación de los esteroides. Se precisa un seguimiento materno continuo luego del parto, ya que se puede presentar empeoramiento de la trombocitopenia y aumento de la LDH hasta 48 horas posparto; sin embargo, si tiene más de 34 semanas, se evidencia sufrimiento fetal o complicaciones maternas, como compromiso orgánico severo (coagulación intravascular diseminada, insuficiencia renal, edema pulmonar, sangrado intrahepático, accidente cerebrovascular o desprendimiento de placenta), la terminación del embarazo debe ser lo más rápido posible $(4,8,15)$. La indicación de trasplante incluye sangrado persistente por hematoma, ruptura o falla hepática. Se encuentra que el $88 \%$ de estas pacientes sobrevive a 5 años luego del trasplante (8).

\section{HEMATOMA, INFARTO Y RUPTURA HEPÁTICA}

La hemorragia y ruptura hepática pueden complicar una preeclampsia, eclampsia o un síndrome HELLP y se ha asociado con una mortalidad del $50 \%$. Las pacientes presentan dolor abdominal, pirexia y choque hipovolémico severo con colapso cardiovascular. Se evidencia aumento marcado de las transaminasas y anemia. La tomografía computarizada y la resonancia magnética son los métodos de elección para el diagnóstico (2).

Los hematomas contenidos pueden ser manejados de forma conservadora con soporte de coagulación agresivo, antibióticos profilácticos y transfusión. Ante cualquier evidencia de inestabilidad hemodinámica se prefiere una angiografía con embolización de la arteria hepática y una intervención quirúrgica tipo empaquetamiento del hígado, ligadura de la arteria hepática y resección.

Los infartos necróticos pueden ocurrir como una complicación de la preeclampsia. A menudo, las pacientes tienen aumentos inexplicados de las transaminasas, fiebre, anemia, leucocitosis y ser asociados con signos de falla hepática. En la mayoría de los casos, el hígado se recupera, pero en otras ocasiones, cuando se presentan áreas de infarto extensas, puede sobrevenir la falla multiorgánica por ruptura hepática y la muerte (2). La ruptura de la cápsula genera sangrado intraperitoneal. La mortalidad es más alta luego de un episodio de ruptura hepática. El tratamiento es reanimación hídrica, manejo quirúrgico o embolización angiográfica, según el casos $(2,4,11)$.

\section{HÍGADO GRASO DEL EMBARAZO}

El hígado graso del embarazo (AFLP) es una patología poco común. Reportes de la literatura informan una incidencia de 1:7 000-15 000 gestaciones. Un estudio poblacional prospectivo, realizado en el Reino Unido con una cohorte de 1,1 millón de gestaciones, estimó una incidencia de 1:20 000 nacimientos $(16,17)$. Esta entidad puede ser potencialmente mortal y se considera una emergencia obstétrica que puede llevar a falla hepática aguda y, si el diagnóstico se retrasa, a la muerte del feto y la madre. Aunque las tasas de mortalidad materna han mejorado considerablemente, pasando de $92 \%$ para antes de 1970 , a tasas menores del $10 \%$ reportadas en 2008 , estas siguen siendo muy altas (2).

Típicamente, esta patología se presenta en el tercer trimestre de la gestación, entre la semana 30 y 38 , pero algunas veces no se reconoce si no hasta después del parto, sin embargo, hay reportes de casos tan tempranos como a las 26 semanas de gestación $(18,19)$. Se caracteriza por ser una enfermedad infiltrativa, con evidencia de esteatosis microvesicular a la biopsia. Es un ejemplo de hepatopatía mitocondrial, que se asocia con la presencia de una mutación homocigótica fetal $(1528 \mathrm{G}>\mathrm{C})$ en el gen que codifica para la hidroxiacil-CoA deshidrogenasa de cadena larga, la cual produce una disminución severa o una pérdida total de la actividad enzimática. Está mutación se traduce en una acumulación de ácidos grasos de cadena larga en la placenta, que luego se derivan a la circulación materna y conducen al desarrollo de daño hepático agudo (20).

Dentro de los factores de riesgo para el desarrollo de AFPL se han descrito historia de un episodio anterior, gestación múltiple, sexo fetal masculino, coexistencia de otras enfermedades hepáticas durante la gestación (HELLP, preeclampsia) y un índice de masa corporal $<20 \mathrm{~kg} / \mathrm{m}^{2}(16$, 17). Los síntomas iniciales de AFPL generalmente son inespecíficos, con 1-2 semanas de náuseas, vómito, dolor abdominal, malestar general y anorexia. Pueden aparecer signos y síntomas de falla hepática aguda (encefalopatía, ictericia y coagulopatía), con desarrollo rápido de hipoglucemia, la cual puede ser moderada/grave. Aproximadamente, el 50\% de estas pacientes cursa con preeclampsia asociada, aunque la hipertensión generalmente no es grave (21).

El método de referencia para el diagnóstico de esta entidad es la biopsia hepática. En los casos en que se presente coagulopatía asociada, esta deberá realizarse vía transyugular, ante el alto riesgo de sangrado, aunque en muchos casos 
no es necesaria para hacer el diagnóstico. El hallazgo histológico característico es la infiltración grasa microvascular, que afecta, de manera característica, la zona pericentral y respeta la zona periportal. Cuando se realiza una biopsia en un estadio precoz de la enfermedad, los hepatocitos tienen una apariencia balonada en ausencia de grandes cantidades de grasa y mitocondrias gigantes. En etapas más tardías, la destrucción hepatocitaria puede causar pérdida del parénquima hepático y atrofia celular (18). No hay una adecuada correlación entre el grado de las alteraciones encontradas en los exámenes de laboratorio y la severidad del compromiso histológico (22).

Las imágenes como la ecografía y la tomografía muestran hallazgos inconsistentes en la detección de la infiltración grasa, por lo que usualmente el diagnóstico se basa en los hallazgos clínicos y de laboratorio. Se han propuesto los criterios de Swansea (Tabla 3) para el diagnóstico del AFLP, estos incluyen síntomas, hallazgos de laboratorio e imágenes. Este modelo, descrito por Ch'ng y colaboradores, fue llevado a cabo en la unidad de obstetricia de Swansea en el suroeste de Gales, Reino Unido en 2002, y luego validado en un estudio de cohortes en 2008; la presencia de al menos 6 de 15 criterios sugiere el diagnóstico de AFPL $(17,23)$. Estos criterios demostraron una sensibilidad del 100\% (IC 95\% 77\%-100\%), una especificidad del 57\% (IC $95 \% 20 \%-88 \%$ ), con un valor predictivo positivo del $85 \%$ y negativo del $100 \%$ para la presencia de esteatosis microvesicular difusa o perivenular (24).

Tabla 3. Criterios de Swansea

\begin{tabular}{lll}
\hline \multicolumn{1}{c}{$\begin{array}{c}\text { Signos y } \\
\text { síntomas }\end{array}$} & Hallazgos de laboratorio & \multicolumn{1}{c}{ Otros } \\
\hline Vómito & Bilirrubina $>0,8 \mathrm{mg} / \mathrm{dL}$ & $\begin{array}{l}\text { Presencia de } \\
\text { ascitis o de "hígado } \\
\text { brillante" a la } \\
\text { ecografía }\end{array}$ \\
Dolor abdominal & Hipoglucemia $<72 \mathrm{mg} / \mathrm{dL}$ & $\begin{array}{l}\text { Biopsia: esteatosis } \\
\text { microvesicular }\end{array}$ \\
Polidipsia/poliuria & Urea elevada $>950 \mathrm{mg} / \mathrm{dL}$ & \\
Encefalopatía & Leucocitosis $>11 \times 10^{9} / \mathrm{L}$ & \\
Ascitis & ALT $>42 \mathrm{U} / \mathrm{L}$ & \\
& Amonio $>66 \mu \mathrm{mol}$ & \\
& Creatinina $>1,7 \mathrm{mg} / \mathrm{dL}$ & \\
& Coagulopatía $\mathrm{TP}>14 \mathrm{~s} \mathrm{o}$ & \\
& TPT $>34 \mathrm{~s}$ & \\
\hline
\end{tabular}

El diagnóstico temprano de esta entidad es esencial. El manejo inicial es básicamente de soporte, con una adecuada estabilización materna, evitar el uso de medicamentos hepatotóxicos y, en caso de sospecha de infección, iniciar antibióticos de amplio espectro. La finalización del emba- razo tan rápido como sea posible, independientemente de la severidad del AFPL, es la base del tratamiento. Si no hay contraindicación obstétrica, el parto puede ser vía vaginal, aunque un estudio pequeño publicado en 2010 demostró una menor mortalidad materna en el grupo de cesárea $v s$. parto vaginal $(16,2 \%$ vs. $48,1 \%)(25,26)$.

El AFPL usualmente es una condición reversible, con una recuperación de la función hepática completa y sin secuelas. En caso de deterioro persistente y desarrollo de falla hepática se deberá considerar la posibilidad de trasplante hepático $(14,16,25)$. En un estudio retrospectivo de 54 pacientes con enfermedad hepática asociada con el embarazo, de los cuales 18 correspondían a diagnóstico de AFPL, referidos a un centro de trasplante hepático, se documentó que la presencia de un lactato elevado $(>2,8$ $\mathrm{mg} / \mathrm{dL}$ ) tenía una sensibilidad del $73 \%$ y una especificidad del 75\% como predictor de muerte o necesidad de trasplante hepático. Cuando se adicionó la presencia de encefalopatía, la sensibilidad y la especificidad incrementaron al $90 \%$ y $86 \%$, respectivamente (27).

\section{HEPATITIS AUTOINMUNE}

La hepatitis autoinmune es un proceso inflamatorio crónico del hígado de causa desconocida, caracterizado por hipergammaglobulinemia, autoanticuerpos circulantes, hepatitis de interfase en la biopsia y respuesta favorable al manejo inmunosupresor (28-30). El espectro clínico es amplio e incluye pacientes asintomáticas, pacientes con síntomas inespecíficos, como fatiga, náuseas, dolor abdominal y artralgias; pacientes con hepatitis aguda severa e incluso pacientes con cirrosis ya establecida $(30,31)$. Algunas pacientes cursan con otras patologías autoinmunes asociadas $(28,30)$.

Los criterios diagnósticos de la hepatitis autoinmune fueron propuestos en 1993 por un grupo de expertos, el Grupo Internacional de Hepatitis Autoinmune (IAIHG) y luego revisados en $1999(30,31)$. Debido a la complejidad de estos criterios, en el 2008, Hennes y colaboradores publicaron un estudio en el que se definió un puntaje simplificado y mucho más práctico a partir de las variables que fueron predictores independientes de hepatitis autoinmune, con sensibilidad y especificidad superior al $80 \%$ (Tabla 4) (29).

En pacientes en gestación, la hepatitis autoinmune se manifiesta y diagnostica igual que en mujeres no embarazadas (8). La hepatitis autoinmune usualmente se presenta en mujeres en edad fértil. Los embarazos exitosos son posibles en este grupo de pacientes; sin embargo, se ha reportado mayor morbilidad y mortalidad tanto para el feto como para la madre, asociados con el pobre control de la actividad inflamatoria 1 año antes de la gestación y durante 
el embarazo (2, 8, 32-38). Estas complicaciones son más frecuentes e incluso mortales en pacientes con cirrosis hepática descompensada $(38,39)$.

Tabla 4. Puntaje simplificado de hepatitis autoinmune (29)

\begin{tabular}{llc}
\hline \multicolumn{1}{c}{ Parámetro } & & Puntaje \\
\hline ANA o ASMA & $\geq 1: 40$ & +1 \\
ANA o ASMA & $\geq 1: 80$ & $+2^{*}$ \\
o LKM & $\geq 1: 40$ & $+2^{*}$ \\
o SLA/LP & Cualquier título & $+2^{*}$ \\
\hline $\lg G$ & $>$ límite superior de lo normal & +1 \\
& $>1,1$ veces el límite superior & +2 \\
\hline Biopsia & Compatible & +1 \\
& Típica & +2 \\
\hline Ausencia de hepatitis & Sí & +2 \\
viral & & \\
\hline
\end{tabular}

${ }^{*}$ El puntaje máximo por autoanticuerpos es +2 . $\geq 6$ puntos: probable.

$\geq 7$ puntos: definitiva.

La activación de la enfermedad es más frecuente en el primer trimestre posparto, con una incidencia de $11 \%-81 \%$, probablemente debido a la reconstitución inmune luego del parto y el descenso de los estrógenos en sangre $(2,8,30,31$, $33,35,37,38)$. Durante el embarazo se ha descrito mejoría e incluso remisión espontánea de la actividad inflamatoria, en probable relación con el estado inmunotolerante que predomina durante la gestación $(30,32,38,39)$. A pesar de esto, la enfermedad puede activarse en cualquier período del embarazo, con una incidencia de $7 \%-21 \%(7,20,30$, 33). Usualmente, esta activación puede controlarse con el aumento de la inmunosupresión; sin embargo, en algunas pacientes, la activación de la enfermedad puede llevar a descompensación hepática, necesidad de trasplante hepático e incluso muerte de la paciente y el feto $(2,33,38)$.

La terapia inmunosupresora con esteroides y agentes, como la azatioprina, son el pilar fundamental del tratamiento de la hepatitis autoinmune $(30,36,40)$. Sin embargo, en el embarazo, el manejo óptimo no está bien establecido, lo que sí está claro es que estas pacientes requieren inmunosupresión estable durante todo el embarazo, con mayor vigilancia en el período posparto $(30,32$, $33,38,40,41)$.

Debido a los efectos teratogénicos reportados en animales, la azatioprina es considerada un medicamento categoría D en gestantes; sin embargo, múltiples estudios retrospectivos han demostrado que es segura en el embarazo y la lactancia; por tanto, el potencial teratogénico de la azatioprina es superado por los efectos benéficos del control de la enfermedad, puesto que la remisión disminuye el riesgo de complicaciones maternas y fetales $(2,8$,
30-33, 35, 37-40). En paciente con hepatitis autoinmune antes del embarazo en manejo con azatioprina, esta debe continuarse en la dosis necesaria para mantener el control de la enfermedad durante la gestación $(2,38)$. En caso de presentarse hepatitis bioquímica, esta se debe tratar de manera convencional con esteroides $(2,8,30)$.

El mofetilo micofenolato debería suspenderse antes del embarazo y no ser utilizado durante la gestación, ya que se ha asociado con aumento de la teratogenicidad $(30,39$, 40). Los inhibidores de calcineurina pueden utilizarse de manera segura durante la gestación, de acuerdo con los datos obtenidos de gestantes trasplantadas $(30,40)$. Con el fin de disminuir los riesgos de complicaciones, estas pacientes idealmente deben planear su embarazo y tener control de la actividad inflamatoria por lo menos 1 año antes de embarazarse, recibir tratamiento durante toda la gestación, recibir atención del parto en centros de alta complejidad y realizar controles estrechos durante el embarazo y el posparto, tanto por obstetricia como por hepatología $(2,30,32,33,38-40)$. La vía del parto se definirá por indicación obstétrica (33).

\section{INFECCIÓN POR VIRUS DE LA HEPATITIS B}

Se ha calculado que hasta un tercio de la población mundial podría tener evidencia serológica de infección pasada o presente por el virus de la hepatitis B (VHB). 350-400 millones de personas son portadoras crónicas del antígeno de superficie ( $\mathrm{HBsAg}$ ) y 240 millones tienen hepatitis crónica (42-44). Cada año se reportan más de 50 millones de casos nuevos, siendo la vertical, la principal forma de transmisión $(42,45)$. Datos de Estados Unidos informan una prevalencia del 0,7-0,9 de gestantes infectadas, lo cual se traduce en 25000 niños en riesgo de infección nacidos anualmente (46).

El riesgo de que la infección por VHB se cronifique, es decir, que el HBsAg persista más allá de 6 meses, se relaciona con el momento en el cual se adquiere la infección, siendo la posibilidad del 5\% en adultos, $50 \%$ en niños pequeños y hasta del $90 \%$ en los lactantes (43). Las tasas más altas de transmisión vertical (70\%-90\%) se han asociado con la presencia materna de los HBsAg y antígeno e ( $\mathrm{HBeAg}$ ), así como a la ausencia de profilaxis posexposición en el lactante (47).

El comportamiento de la infección por VHB en el embarazo no tiene diferencias importantes, cuando este se compara con la población general, $95 \%$ de las gestantes resuelve la infección aguda de manera espontánea y el riesgo de falla hepática es cercano al 1\% (48). Si la infección se presenta en la etapa temprana de la gestación, esta podría causar aborto espontáneo, pero, por lo general, se resuelve sin consecuencias para la madre o el feto. En este escenario, la 
posibilidad de transmisión vertical es de solo el $10 \%$, sin embargo, cuando esta infección se adquiere en la etapa final del embarazo, la transmisión vertical tiene una incidencia mucho más alta, la cual puede ser hasta del $60 \%$ (49). Son varios los factores que aumentan la posibilidad de que ocurra la transmisión perinatal del VHB (50-52):

- Se ha demostrado que la inmunoprofilaxis puede fallar en presencia de carga virales maternas altas (en especial cuando estas son $>6 \log _{10}$ copias $\left./ \mathrm{mL}\right)(51-53)$

- La presencia de HBeAg, considerado como marcador de replicación e infectividad, que usualmente se asocia con cargas virales elevadas

- La falta de inmunoprofilaxis se relaciona con una posibilidad de transmisión perinatal $>90 \%$, si la madre es $\mathrm{HBeAg}$ positiva, y en el $15 \%$, si es HBeAg negativa. Si se ofrece una adecuada inmunoprofilaxis, la tasa de transmisión perinatal cae al $2 \%$. La gran mayoría de estos casos se da cuando las cargas virales son superiores a $200000 \mathrm{UI} / \mathrm{mL}\left(10^{6}\right.$ copias $\left./ \mathrm{mL}\right)(49-54)$.

La prevención de la transmisión vertical se fundamenta en la combinación de vacunación e inmunoglobulina contra la hepatitis B (HBIG), las cuales deberán ser proveídas dentro de las primeras 12 horas después del nacimiento a todo niño nacido de madre $\mathrm{HBsAg}$ positivo, independientemente de que ella reciba o no tratamiento antiviral (55, 57). Esta combinación genera un gran impacto sobre las tasas de transmisión viral y ha hecho que la transmisión perinatal pase de un 90\% (en los casos en los que no se administra inmunoprofilaxis) a menos $10 \%$ en presencia de esta combinación (49).

El tratamiento antiviral está indicado en toda gestante HBsAg positivo, con carga viral $>200000 \mathrm{UI} / \mathrm{mL}\left(>10^{6}\right.$ copias $/ \mathrm{mL}$ ). En estas pacientes, el uso de la inmunoprofilaxis sola tiene una posibilidad de falla que puede llegar a ser hasta del $30 \%$, por lo que se consideran un grupo de alto riesgo para la transmisión perinatal $(49,57,58)$. En las pacientes con infección crónica por VHB HBeAg negativo (antes llamado estado de portador asintomático) y con cargas virales $\leq 200000 \mathrm{UI} / \mathrm{mL}$, no está indicada la profilaxis antiviral $(59,60)$.

Los objetivos del tratamiento en el embarazo son mantener la función hepática estable en la madre y prevenir la infección neonatal; por tanto, los niveles de aminotransferasas deberán ser evaluados regularmente durante la gestación. El medicamento antiviral se debe iniciar entre la semana 28 a 32 de gestación, ya que para esta etapa, la organogénesis está completa y contamos con el tiempo suficiente para lograr que los niveles de $\mathrm{ADN}$ del VHB disminuyan de manera importante (60). El medicamento deberá continuarse hasta 12 semanas después del parto, debido a la posibilidad de exacerbación del VHB, el cual se presenta de manera más frecuente en las pacientes que son $\mathrm{HBeAg}$ positivas (riesgo que es 2,56 veces mayor cuando se compara con las HBeAg negativas) (59-62).

Se disponen de 3 medicamentos antivirales para uso durante la gestación, los cuales cuentan con un adecuado perfil de seguridad en el feto, estos son lamivudina, telbivudina y tenofovir (63-66). La lamivudina ha ido cayendo en desuso por las altas tasas de resistencia, que puede ser del $70 \%$ a 5 años. Este fármaco limita las opciones futuras de tratamiento materno, ya que incluso su uso por un corto período promueve variantes virales resistentes en $20 \%$ de los casos (67).

El tenofovir es el agente antiviral de elección durante la gestación, el cual deberá administrarse en dosis de $300 \mathrm{mg} /$ día vía oral. Este es el análogo nucleósido más potente, tiene las menores tasas de resistencia y se dispone de amplios datos de seguridad para su uso durante el embarazo (49, $64,68,69)$. En pacientes con historia de infección crónica por VHB que vienen en manejo con tenofovir deberán continuar con este medicamento, si reciben entecavir se deberá rotar el tratamiento a tenofovir (59).

La indicación del parto es obstétrica, sin contraindicación para la vía vaginal, ya que los estudios no han encontrado beneficios en la cesárea para disminuir la posibilidad de transmisión perinatal $(70,71)$. Tampoco hay contraindicación para la lactancia materna en las mujeres no tratadas, ni en aquellas madres que reciben un agente antiviral como el tenofovir, ya que incluso el riesgo de exposición a este medicamento in utero es mayor que a través de la leche materna y su uso se recomienda durante el embarazo (59, 72-75). Lo que sí es claro es que deberá evitarse la lactancia en presencia de pezones agrietados o sangrantes, esto favorece la mezcla de exudados serosos con la leche materna y podría potencialmente llevar a la transmisión del VHB al lactante (76).

\section{INFECCIÓN POR VIRUS DE LA HEPATITIS C}

La infección por el virus de la hepatitis C (VHC) es una de las principales causas de enfermedad hepática crónica en todo el mundo (77). La historia natural de esta entidad es muy variable y puede ir desde cambios histológicos mínimos hasta la cirrosis, con o sin carcinoma hepatocelular. Hay aproximadamente 71 millones de personas infectadas de forma crónica por VHC en el mundo. Se estima que entre el 1\%-8\% de las mujeres gestantes están infectadas por el VHC (78).

La transmisión de la infección de la madre al hijo puede ocurrir durante tres períodos distintos:

- Período intrauterino: definido por la presencia de ARN del VHC en suero del recién nacido dentro de los primeros 3 días de vida. Da cuenta del 30\%-40\% de 
los casos. Dentro de los mecanismos propuestos se encuentran el paso de partículas virales de la madre al feto, flujo materno-fetal de células mononucleares infectadas e infección de los trofoblastos

- Período periparto: en este, el ARN del VHC se encuentra en el suero del recién nacido 28 días después del nacimiento. Este es el período más importante en la transmisión vertical ( $60 \%$ de los casos). Se correlaciona con la exposición a sangre materna. Para este período, los principales factores de riesgo son los procedimientos invasivos obstétricos (por ejemplo, amniocentesis y monitorización fetal), así como las laceraciones de la mucosa vaginal o perineal durante el parto vaginal y la ruptura prolongada de las membranas

- Período posparto: la transmisión durante este período es rara y se atribuye a la lactancia materna. Sin embargo, a pesar de que el ARN del VHC es detectable en el calostro humano, la lactancia no se considera un factor de riesgo para la transmisión de madre a hijo (79).

Un metaanálisis publicado en 2014 informó tasas de transmisión vertical de 5,8\% en mujeres virémicas y de 10,8\% cuando hay coinfección con el VIH (80). La transmisión ocurre casi exclusivamente de madres que son ARN-VHC positivas y el riesgo se correlaciona con los títulos de carga viral de la madre, siendo la transmisión 4 veces más alta cuando esta es $>6 \log$ copias $/ \mathrm{mL}$ al compararse con aquellas que tienen carga virales más bajas $(14,3 \%$ vs. $3,9 \%$, respectivamente) (81).

No hay un consenso universal sobre el tamizaje de VHC durante la gestación. El Colegio Americano de Ginecología y Obstetricia (ACOG) y el Centro para el Control y Prevención de Enfermedades (CDC) recomiendan el tamizaje solo en mujeres con factores de riesgo para infección por VHC (Tabla 5) (79). Sin embargo, en un estudio retrospectivo, donde Selvapatt y colaboradores evaluaron 35355 mujeres que se sometieron a una prueba prenatal de detección del VHC se confirmaron un total de 136 maternas con resultados positivos para anticuerpos contra VHC $(0,38 \%)$, de las cuales $44(0,12 \%)$ fueron recientemente diagnosticadas con hepatitis $\mathrm{C}$ crónica, 34 ya tenían un diagnóstico previo y 58 tenían carga viral para VHC negativa. En los hijos de las madres recién diagnosticadas se logró documentar 3 casos de transmisión vertical $(6,8 \%)$. Este y otros estudios han demostrado que la tamización universal en la gestación se debería implementar $(82,83)$.

No hay evidencia de que la finalización del embarazo por cesárea disminuya la posibilidad de transmisión del VHC y la lactancia materna no está contraindicada, a menos de que se presenten pezones agrietados o sangrantes, como es la recomendación también en VHB (85).
Tabla 5. Recomendaciones para tamizaje prenatal de VHC (84)

Recomendaciones para tamizaje prenatal de VHC

Uso de drogas intravenosas ilegales (actual o pasado, incluso

aquellas personas que se inyectaron solo una vez)

Uso de drogas ilícitas intranasales

Uso de hemodiálisis

Historia de piercing o tatuajes en un entorno no regulado

Infección por VIH o VHB

Receptoras de transfusiones o trasplantes antes de 1992 o factores

de coagulación antes de 1987

Antecedentes de encarcelamiento

Fertilización in vitro con donantes anónimos

Parejas sexuales de personas con VIH, VHB o VHC

Mujeres con enfermedad hepática crónica inexplicada (incluida ALT persistentemente elevada)

En cuanto al tratamiento, el uso de interferón y ribavirina está contraindicado en el embarazo por sus efectos teratogénicos (86). No hay datos adecuados en humanos para el uso de los antivirales de acción directa de segunda generación en el embarazo, sin embargo, los datos obtenidos de estudios en animales demuestran que no confieren un riesgo para el feto. Debido a la falta de estudios en humanos, aún no se ha aprobado ninguna terapia antiviral de acción directa para tratar la infección por el VHC en el embarazo (87).

\section{CIRROSIS Y EMBARAZO}

La prevalencia de cirrosis en mujeres en edad fértil es baja, debido a que el daño hepatocelular lleva a alteraciones metabólicas y hormonales, como anovulación, amenorrea e infertilidad $(8,10,11,32)$. Por tanto, el embarazo en pacientes con enfermedad hepática es poco frecuente, pero cuando se presenta implica una condición clínica complicada (8). Los resultados del embarazo están relacionados con la severidad de la enfermedad hepática. Un puntaje MELD preconcepcional $\geq 10$ puntos se asocia con un riesgo de descompensación del $10 \%$, mientras que un puntaje MELD inferior a 6 puntos no se asocia con complicaciones hepáticas durante el embarazo $(2,7)$.

Las causas más frecuentes de cirrosis en las mujeres embarazadas son la infección por virus hepatotropos y la autoinmunidad (10). Los cambios fisiológicos del embarazo y las necesidades fetales empeoran la hipertensión portal e incrementan los riesgos tanto maternos como fetales $(2,7,10)$. El sangrado variceal es la complicación más frecuente y catastrófica de la hipertensión portal durante el embarazo, con mayor riesgo de sangrado en el segundo trimestre, momento en el que se alcanza el pico más alto de 
hipertensión portal, así como al momento del parto por las maniobras de Valsalva $(7,8)$.

El aumento del volumen sanguíneo y gasto cardíaco materno, asociado con una disminución de la resistencia vascular periférica secundaria al efecto de la progesterona y el desarrollo del lecho vascular placentario, llevan a un estado hiperdinámico con aumento del flujo a las colaterales, lo que incrementa de manera importante el riesgo de sangrado variceal (10). Además, la compresión externa de la vena cava inferior por el útero grávido incrementa aún más la presión portal (8). Las mujeres cirróticas embarazadas tienen una probabilidad cercana del $30 \%$ de sangrado variceal, que incrementa en pacientes con varices preexistentes a un $70 \%(8,10,32)$. La mortalidad asociada con el sangrado es del $18 \%-50 \%(2,10)$. El sangrado variceal incrementa la incidencia de aborto y parto pretérmino. Ante el alto riesgo de sangrado variceal y sus complicaciones, el Colegio Americano de Gastroenterología recomienda el tamizaje de varices esofágicas en pacientes embarazadas en el segundo trimestre, después de completar la organogénesis y antes del parto, momento de mayor riesgo de sangrado.

A pesar de los datos limitados en cuanto a la profilaxis y el manejo del sangrado variceal agudo en pacientes embarazadas, la profilaxis primaria, al igual que en la población general, puede realizarse con ligadura endoscópica o con bloqueantes $\beta$ (10). La profilaxis secundaria requiere tanto la ligadura endoscópica con bandas como el uso de bloqueantes $\beta$. Estos medicamentos son considerados seguros en el embarazo a pesar de ser categoría $C$, con riesgo de bradicardia fetal, restricción del crecimiento intrauterino e hipoglucemia neonatal $(2,7,10)$. En caso de presentarse con sangrado variceal agudo, el tratamiento es similar al de la población general. Se debe realizar adecuada reanimación y estabilización de la madre. La ligadura endoscópica de las varices es la principal medida terapéutica. La endoscopia es segura en el embarazo, con un pequeño riesgo de hipoxia fetal secundaria a la sedación y la posición de la paciente. El octreotide es un medicamento categoría B en el embarazo $y$, a pesar de no tener buenos estudios en mujeres embarazadas, parece ser seguro. La terlipresina es categoría $\mathrm{D}$, ya que produce isquemia uterina; por tanto, no se recomienda su uso en mujeres embarazadas (2). Los antibióticos profilácticos recomendados son las cefalosporinas de tercera generación, ya que las quinolonas están contraindicadas (10). El TIPS de emergencia ha sido realizado con éxito en pacientes embarazadas $(2,32)$.

La ascitis y la encefalopatía hepática se presentan en el $24 \%$ de las pacientes embarazadas con cirrosis y pueden aparecer en todas las etapas de la gestación (88). El tratamiento de la ascitis se basa en la restricción de sal y uso de diuréticos. En caso de documentarse peritonitis bacteriana espontánea, el tratamiento usual es con cefalosporinas de tercera generación (10). La encefalopatía hepática usualmente está asociada con un evento precipitante que debe buscarse activamente. La lactulosa es un medicamento categoría B, mientras que la rifaximina es categoría C (32).

En pacientes embarazadas que requieren imágenes para visualizar el parénquima hepático e incluso la vía biliar, la ecografía es considerada el método más seguro. En caso de requerir una imagen más detallada, la resonancia magnética sin contraste también es segura en el segundo y tercer trimestre del embarazo, siempre teniendo en cuenta la limitación de las imágenes no contrastadas para la valoración de las lesiones hepáticas, principalmente el hepatocarcinoma $(8,11)$. No hay datos suficientes para recomendar parto por vía vaginal o cesárea en estas pacientes, por lo que la indicación de esta última será de tipo obstétrico $(2,89)$.

Las pacientes embarazadas con cirrosis tienen mayor riesgo de hemorragia posparto, esta se presenta en el 7\%-10\% de los casos en relación con la coagulopatía secundaria a disfunción hepática y la trombocitopenia por hiperesplenismo. El tratamiento es con soporte transfusional y con agentes que favorecen la contracción uterina (10). En cuanto a las complicaciones fetales, el aborto espontáneo, parto pretérmino, los mortinatos y la muerte perinatal están incrementados $(2,7,89)$.

Debido al alto riesgo de complicaciones descritas, el manejo integral de estas pacientes requiere un grupo interdisciplinario en un centro de alto nivel de complejidad, que cuente con ginecólogos, neonatólogos, hepatólogos, endoscopistas e incluso intensivistas. Idealmente, estas pacientes deben estar compensadas de su enfermedad hepática, las varices esofágicas manejadas y los medicamentos contraindicados en el embarazo deben ser suspendidos, con seguimientos periódicos durante el embarazo, con el fin de disminuir el riesgo de complicaciones tanto para la madre como para el feto.

\section{TRASPLANTE Y EMBARAZO}

Los desenlaces perinatales en mujeres con trasplante hepático son buenos, sobre todo si esperan al menos 12 meses luego de la cirugía o de un episodio agudo de rechazo para embarazarse, esto pensando en que se tenga menores dosis de inmunosupresores y menos riesgo de infecciones oportunistas. La tasa de nacidos vivos está reportada entre el 70\%-90\%. Hay un alto riesgo de desarrollar trastornos hipertensivos del embarazo y preeclampsia, además de riesgo de parto pretérmino y bajo peso al nacer $(11,12)$.

Los cuidados previos al embarazo deben incluir continuar la medicación inmunosupresora y los suplementos de ácido fólico en altas dosis ( $5 \mathrm{mg} /$ día) (12). En general, el impacto de los esteroides, azatioprina e inhibidores de calcineurina (tacrolimus y ciclosporina) en anormalidades 
materno-fetales es pequeño. Con azatioprina se ha visto leucopenia neonatal, la cual se normaliza después del primer año de vida, además de bajo peso al nacer y prematuridad, la ciclosporina está asociada con bajo peso al nacer y los inhibidores de calcineurina pueden producir hiperpotasemia, parto pretérmino y disfunción renal $(4,11,90,91)$.

En contraste, el micofenolato, sirolimus y everolimus están asociados con altas tasas de anormalidades fetales. El micofenolato no solo aumenta la tasa de abortos, sino que está relacionado con múltiples malformaciones en oídos, extremidades, riñones, corazón, esófago y maxilofaciales, como paladar hendido y labio leporino, toxicidad fetal. El sirolimus y everolimus no tiene estudios suficientes, pero por su efecto antiproliferativo puede dañar al feto, por lo que están contraindicados en el embarazo. Si es posible, la materna que reciba este tipo de inmunosupresores debe recibir regímenes alternos a estos medicamentos, cambiándolos mínimo 6 meses antes de la concepción $(4,11,90,91)$.

La sobrevida del injerto parece no verse afectada por el embarazo, a pesar de los reportes de rechazo, que van del $2 \%-17 \%$ durante el embarazo y del $3 \%-12 \%$ en el posparto. Los episodios de rechazo se manejan como en las mujeres no embarazadas, con investigación de la causa del rechazo y ajuste de la inmunosupresión $(2,12)$.

El control prenatal se debe hacer cada 4 semanas, siempre con tamizaje para las infecciones normales del embarazo, actualizar las vacunas, pero incluir también evaluaciones periódicas en busca de citomegalovirus, el cual no solo puede generar varias malformaciones en el desarrollo fetal, sino también comprometer la sobrevida del injerto. Una vez se llegue a las 24 semanas se recomienda la realización de monitorización de bienestar fetal cada 2 semanas, incluido Doppler de las arterias umbilicales y uterinas. Se deberá buscar que las maternas trasplantadas tengan un nivel de hemoglobina entre 10-12 g/dL, para lograr esto se recomienda el uso de hierro y agentes estimulantes de la eritropoyetina, los cuales no están contraindicados en el embarazo $(90,91)$.

Cuando se revisan los estudios más grandes publicados sobre embarazos en pacientes con trasplantes hepáticos se encuentra que las complicaciones maternas durante el embarazo son hipertensión $(33,9 \%)$, infecciones $(26,5 \%)$, preeclampsia $(21,5 \%)$, rechazo $(8,4 \%)$ y diabetes $(6,7 \%)$ (90). Se prefiere parto por cesárea principalmente por preocupación a complicaciones obstétricas (92).

Se permite la lactancia materna a las mujeres que están en manejo solo con esteroides, pero, como la gran mayoría tienen más de un medicamento inmunosupresor, no se aconseja la alimentación materna, ya que se desconocen algunos efectos de la inmunosupresión sobre el recién nacido $(4,91)$.

Los anticonceptivos hormonales en pacientes con trasplante de hígado no tienen efectos en la función hepática, incidencia de rechazo, complicaciones, cardiovasculares o descontinuación de los medicamentos; sin embargo, se puede desarrollar toxicidad por inhibidores de calcineurina asociado con inhibición del citocromo P-450 por los anticonceptivos orales; por lo cual las mujeres con trasplante hepático que planifican con estos medicamentos requieren control estricto de niveles de ciclosporina y tacrolimus. El método anticonceptivo más usado en estas pacientes son los dispositivos intrauterinos, ya que son seguros para la viabilidad del injerto y no aumentan el riesgo de infecciones intrauterinas en esta población (90-92).

\section{REFERENCIAS}

1. Lai M, Wolf J. The liver in pregnancy. Handbook of Liver Disease. Elsevier. 2018. p. 308-23. Disponible en: https:// doi.org/10.1016/B978-0-323-47874-8.00023-7.

2. Westbrook R, Dusheiko G, Williamson C. Pregnancy and liver disease. J Hepatol. 2016;64(4):933-45. doi: https:// doi.org/10.1016/j.jhep.2015.11.030.

3. Shekhar S, Diddi G. Liver disease in pregnancy. Taiwan J Obstet Gynecol. 2015;54(5):475-82. doi: https://doi. org/10.1016/j.tjog.2015.01.004.

4. Than N, Neuberger J. Liver abnormalities in pregnancy. Best Pract Res Clin Gastroenterol. 2013;27(4):565-75. doi: https://doi.org/10.1016/j.bpg.2013.06.015.

5. Clinical management guidelines for obstetrician-gynecologists. Number 153, September 2015: (replaces practice bulletin number 52, April 2004). Obstet Gynecol. 2003;126(12):12-24.

6. London V,GrubeS, ShererD,Abulafia O.Hyperemesisgravidarum: a review of recent literature. Pharmacology. 2017; 100(34):161-71. doi: https://doi.org/10.1159/000477853.

7. Westbrook R, Yeoman A, O’Grady J, Harrison P, Devlin J, Heneghan M. Model for end-stage liver disease score predicts outcome in cirrhotic patients during pregnancy. Clin Gastroenterol Hepatol. 2011;9(8):694-9. doi: https://doi. org/10.1016/j.cgh.2011.03.036.

8. Deepak J, Andra J, Quaglia A, Westbrook R, Heneghan M. Liver disease in pregnancy. Lancet. 2010;375:594-605. doi: https://doi.org/10.1016/S0140-6736(09)61495-1.

9. Management of hyperemesis gravidarum. Drug Ther Bull. 2013;51(11):126-9. doi: https://doi.org/10.1136/ dtb.2013.11.0215.

10. Aggarwal N, Negi N, Aggarwal A, Bodh V, Dhiman R. Pregnancy with portal hypertension. J Clin Exp Hepatol. 2014;4(2):163-71. doi: https://doi.org/10.1016/j. jceh.2014.05.014.

11. Tran T, Ahn J, Reau N. ACG clinical guideline: liver disease and pregnancy. Am J Gastroenterol. 2016;111(2):176-94. doi: https://doi.org/10.1038/ajg.2015.430.

12. Geenes V, Williamson C. Gastrointestinal and liver disease in pregnancy. Obstet Gynaecol Reprod Med. 2017;27(3):918. doi: https://doi.org/10.1016/j.ogrm.2017.01.005.

13. Frise $C$, Williamson C. Liver disease in pregnancy. Medicine (Baltimore). 2015;43(11):636-8. doi: https://doi. org/10.1016/j.mpmed.2015.08.010. 
14. Geenes V, Williamson C. Liver disease in pregnancy. Best Pract Res Clin Obstet Gynaecol. 2015;29(5):612-24. doi: https://doi.org/10.1016/j.bpobgyn.2015.04.003.

15. Ditisheim A, Sibai B. Diagnosis and management of HELLP syndrome complicated by liver hematoma. Clin Obstet Gynecol. 2017;60(1):190-7. doi: https://doi.org/10.1097/ GRF.0000000000000253.

16. Liu J, Ghaziani T, Wolf L. Acute fatty liver disease of pregnancy: updates in pathogenesis, diagnosis, and management. Am J Gastroenterol. 2017;112(6):838-46. doi: https://doi. org/10.1038/ajg.2017.54.

17. Knight M, Nelson-Piercy C, Kurinczuk J, Spark P, Brocklehurst P, UK Obstetric Surveillance System. A prospective national study of acute fatty liver of pregnancy in the UK. Gut. 2008;57(7):951-6. doi: https://doi.org/10.1136/ gut.2008.148676.

18. Papafragkakis H, Singhal S, Anand S. Acute fatty liver of pregnancy. South Med J. 2013;106(10):588-93. doi: https://doi.org/10.1097/SMJ.0000000000000007.

19. Buytaert I, Elewaut G, van Kets H. Early occurrence of acute fatty liver in pregnancy. Am J Gastroenterol. 1996;91(3):603-4.

20. Natarajan S, Ibdah J. Role of 3-hydroxy fatty acid-induced hepatic lipotoxicity in acute fatty liver of pregnancy. Int J Mol Sci. 2018;19(1):1-17. doi: https://doi.org/10.3390/ ijms 19010322 .

21. Lee N, Brady C. Liver disease in pregnancy. World J Gastroenterol. 2009;15(8):897-906. doi: https://doi. org/10.3748/wjg.15.897.

22. Steingrub J. Pregnancy-associated severe liver dysfunction. Crit Care Clin. 2004;20(4):763-76. doi: https://doi. org/10.1016/j.ccc.2004.05.006.

23. Ch'ng C, Morgan M, Hainsworth I, Kingham J. Prospective study of liver dysfunction in pregnancy in Southwest Wales. Gut. 2002;51(6):876-80. doi: https://doi.org/10.1136/ gut.51.6.876.

24. Maléth J, Venglovecz V, Rázga Z, Tiszlavicz L, Rakonczay Z, Hegyi P. Non-conjugated chenodeoxycholate induces severe mitochondrial damage and inhibits bicarbonate transport in pancreatic duct cells. Gut. 2011;60(1):136-8. doi: https://doi.org/10.1136/gut.2009.192153.

25. Remiszewski P, Pawlak J, Skwarek A, Grzelak I, Patkowski W, Grodzicki M, et al. Orthotopic liver transplantation for acute liver failure resulting from «acute fatty liver of pregnancy». Ann Transplant. 2003;8(3):8-11.

26. Wei Q, Zhang L, Liu X. Clinical diagnosis and treatment of acute fatty liver of pregnancy: a literature review and 11 new cases. J Obstet Gynaecol Res. 2010;36(4):751-6. doi: https://doi.org/10.1111/j.1447-0756.2010.01242.x.

27. Westbrook R, Yeoman A, Joshi D, Heaton N, Quaglia A, OGrady JG, et al. Outcomes of severe pregnancyrelated liver disease: refining the role of transplantation. Am J Transplant. 2010;10(11):2520-6. doi: https://doi. org/10.1111/j.1600-6143.2010.03301.x.

28. Gatselis N, Zachou K, Koukoulis G, Dalekos G. Autoimmune hepatitis, one disease with many faces: etio- pathogenetic, clinico-laboratory and histological characteristics. World J Gastroenterol. 2015;21(1):60. doi: https:// doi.org/10.3748/wjg.v21.i1.60.

29. Hennes E, Zeniya M, Czaja A, Parés A, Dalekos G, Krawitt EL, et al. Simplified criteria for the diagnosis of autoimmune hepatitis. Hepatology. 2008;48(1):169-76. doi: https://doi. org/10.1002/hep.22322.

30. European Association for the Study of the Liver. EASL Clinical Practice Guidelines: autoimmune hepatitis. J Hepatol. 2015;63(4):971-1004. doi: https://doi. org/10.1016/j.jhep.2015.06.030.

31. Manns M, Czaja A, Gorham J, Krawitt E, Mieli-Vergani G, Vergani $D$, et al. Diagnosis and management of autoimmune hepatitis. Hepatology. 2010;51(6):2193-213. doi: https:// doi.org/10.1002/hep.23584.

32. Almashhrawi A, Khulood A, Rubayat R, Ghassan H, Jamal I. Liver diseases in pregnancy: diseases not unique to pregnancy. World J Gastroenterol. 2013;19(43):7630. doi: https://doi.org/10.3748/wjg.v19.i43.7630.

33. Braga A, Vasconcelos C, Braga J. Pregnancy with autoimmune hepatitis. Bed Bench. 2016;9(3):220-4.

34. Schmeltzer P, Russo M. Clinical narrative: autoimmune hepatitis. Am J Gastroenterol. 2018;113(7):951-8. doi: https://doi.org/10.1038/s41395-018-0058-z.

35. Schramm C, Herkel J, Beuers U, Kanzler S, Galle P, Lohse A. Pregnancy in autoimmune hepatitis: outcome and risk factors. Am J Gastroenterol. 2006;101(3):556-60. doi: 10.1111/j.1572-0241.2006.00479.x.

36. Orgul G, Ozkan E, Celik H, Beksac M. Autoimmune hepatitis and pregnancy: report of two cases with different maternal outcomes. Clin Exp Hepatol. 2017;4:212-4. doi: https://doi.org/10.5114/ceh.2017.71445.

37. Heneghan M, Norris S, O'Grady J, Harrison P, McFalane I. Management and outcome of pregnancy in autoimmune hepatitis. Gut. 2001;48(1):97-102. doi: https://doi. org/10.1136/gut.48.1.97.

38. Westbrook R, Yeoman A, Kriese S, Heneghan M. Outcomes of pregnancy in women with autoimmune hepatitis. J Autoimmun. 2012;38(2-3):J239-44. doi: https://doi. org/10.1016/j.jaut.2011.12.002.

39. Bremer L, Schramm C, Tiegs G. Immunology of hepatic diseases during pregnancy. Semin Immunopathol. 2016;38(6):66985. doi: https://doi.org/10.1007/s00281-016-0573-1.

40. Sebode M, Schramm C. AIH: which alternative for difficultto-treat patients? Dig Dis. 2015;33(2):83-7. doi: https:// doi.org/10.1159/000440752.

41. Lammert C, Loy V, Oshima K, Gawrieh S. Management of difficult cases of autoimmune hepatitis. Curr Gastroenterol Rep. 2016;18(2). doi: http://link.springer.com/10.1007/ s11894-015-0484-7.

42. Terrault N, Bzowej N, Chang KM, Hwang J, Jonas M, Murad $\mathrm{M}$, et al. AASLD guidelines for treatment of chronic hepatitis B. Hepatol Baltim Md. 2016;63(1):261-83. doi: https:// doi.org/10.1002/hep.28156.

43. Association E. EASL clinical practice guidelines: management of chronic hepatitis B virus infection. J Hepatol. 
2012;57(1):167-85. doi: https://doi.org/10.1016/j. jhep.2012.02.010.

44. Lavanchy D. Hepatitis B virus epidemiology, disease burden, treatment, and current and emerging prevention and control measures. J Viral Hepat. 2004;11:97-107. doi: https:// doi.org/10.1046/j.1365-2893.2003.00487.x.

45. Tran T. Hepatitis B in pregnancy. Clin Infect Dis. 2016;62(4):S314-7. doi: https://doi.org/10.1093/cid/ ciw092.

46. Dionne-Odom J, Tita A, Silverman N. Hepatitis B in pregnancy screening, treatment, and prevention of vertical transmission. Am J Obstet Gynecol. 2016;214(6-14).

47. Patton H, Tran T. Management of hepatitis B during pregnancy. Nat Rev Gastroenterol Hepatol. 2014;11(7):402-9. doi: https://doi.org/10.1038/nrgastro.2014.30.

48. Rac M, Sheffield J. Prevention and management of viral hepatitis in pregnancy. Obstet Gynecol Clin N Am. 2014;41:57392. doi: https://doi.org/10.1016/j.ogc.2014.08.004.

49. Castillo E, Murphy K, van SchalkwykJ. Hepatitis B and pregnancy. J Obstet Gynaecol Can JOGC J. 2017;39(3):181-90. doi: https://doi.org/10.1016/j.jogc.2016.11.001.

50. Liu CP, Zeng YL, Zhou M, Chen LL, Hu R, Wang L, et al. Factors associated with mother-to-child transmission of hepatitis B virus despite immunoprophylaxis. Intern Med Tokyo Jpn. 2015;54(7):711-6. doi: https://doi. org/10.2169/internalmedicine.54.3514.

51. Wen WH, Chang MH, Zhao LL, Ni YH, Hsu HY, Wu JF, et al. Mother-to-infant transmission of hepatitis $\mathrm{B}$ virus infection: significance of maternal viral load and strategies for intervention. J Hepatol. 2013;59(1):24-30. doi: https:// doi.org/10.1016/j.jhep.2013.02.015.

52. Lu LL, Chen BX, Wang J, Wang D, Ji Y, Yi HG, et al. Maternal transmission risk and antibody levels against hepatitis $B$ virus e antigen in pregnant women. Int J Infect Dis Off Publ Int Soc Infect Dis. 2014;28:41-4. doi: https://doi. org/10.1016/j.ijid.2014.07.028.

53. Zou H, Chen Y, Duan Z, Zhang H, Pan C. Virologic factors associated with failure to passive-active immunoprophylaxis in infants born to HBsAg-positive mothers. J Viral Hepat. 2012;19(2):18-25. doi: https://doi.org/10.1111/j.13652893.2011.01492.x.

54. Ott J, Stevens G, Wiersma S. The risk of perinatal hepatitis B virus transmission: hepatitis $\mathrm{B}$ e antigen ( $\mathrm{HBeAg}$ ) prevalence estimates for all world regions. BMC Infect Dis. 2012;12:131. doi: https://doi.org/10.1186/1471-2334-12-131.

55. Lee C, Gong Y,BrokJ,BoxallE, Gluud C. Hepatitis Bimmunisation for newborn infants of hepatitis B surface antigen-positive mothers. Cochrane Database Syst Rev. 2006; (2):CD004790. doi: https://doi.org/10.1002/14651858.CD004790.pub2.

56. Beasley R, Hwang L, Lee G, Lan C, Roan C, Huang F, et al. Prevention of perinatally transmitted hepatitis $\mathrm{B}$ virus infections with hepatitis B immune globulin and hepatitis B vaccine. Lancet Lond Engl. 1983;2(8359):1099-102. doi: https://doi.org/10.1016/S0140-6736(83)90624-4.

57. Pan C, Duan ZP, Bhamidimarri K, Zou HB, Liang XF, Li $\mathrm{J}$, et al. An algorithm for risk assessment and intervention of mother to child transmission of hepatitis B virus. Clin Gastroenterol Hepatol Off Clin Pract J Am Gastroenterol Assoc. 2012;10(5):452-9. doi: https://doi.org/10.1016/j. cgh.2011.10.041.

58. Brown R, McMahon B, Lok A, Wong J, Ahmed A, Mouchli $\mathrm{M}$, et al. Antiviral therapy in chronic hepatitis $\mathrm{B}$ viral infection during pregnancy: a systematic review and meta-analysis. Hepatol Baltim Md. 2016;63(1):319-33. doi: https:// doi.org/10.1002/hep.28302.

59. European Association for the Study of the Liver. Electronic address: easloffice@easloffice.eu, European Association for the Study of the Liver. EASL 2017 Clinical Practice Guidelines on the management of hepatitis B virus infection. J Hepatol. 2017;67(2):370-98. doi: 10.1016/j. jhep.2017.03.021.

60. Shao Z, Al Tibi M, Wakim-Fleming J. Update on viral hepatitis in pregnancy. Cleve Clin J Med. 2017;84(3):202-6. doi: https://doi.org/10.3949/ccjm.84a.15139.

61. Chang C, Aziz N, Poongkunran M, Javaid A, Trinh H, Lau $D$, et al. Serum alanine aminotransferase and hepatitis B DNA flares in pregnant and postpartum women with chronic hepatitis B. Am J Gastroenterol. 2016;111(10):1410-5. doi: https://doi.org/10.1038/ajg.2016.296.

62. Giles M, Visvanathan K, Lewin S, Bowden S, Locarnini $\mathrm{S}$, Spelman T, et al. Clinical and virological predictors of hepatic flares in pregnant women with chronic hepatitis $B$. Gut. 2015;64(11):1810-5. doi: https://doi.org/10.1136/ gutjnl-2014-308211.

63. Wu Q, Huang H, Sun X, Pan M, He Y, Tan S, et al. Telbivudine prevents vertical transmission of hepatitis $\mathrm{B}$ virus from women with high viral loads: a prospective longterm study. Clin Gastroenterol Hepatol Off Clin Pract J Am Gastroenterol Assoc. 2015;13(6):1170-6. doi: https://doi. org/10.1016/j.cgh.2014.08.043.

64. Pan C, Duan Z, Dai E, Zhang S, Han G, Wang Y, et al. Tenofovir to prevent hepatitis B transmission in mothers with high viral load. N Engl J Med. 2016;374(24):2324-34. doi: https://doi.org/10.1056/NEJMoa1508660.

65. Deng M, Zhou X, Gao S, Yang SG, Wang B, Chen HZ, et al. The effects of telbivudine in late pregnancy to prevent intrauterine transmission of the hepatitis B virus: a systematic review and meta-analysis. Virol J. 2012;9:185. doi: https:// doi.org/10.1186/1743-422X-9-185.

66. Sarkar M, Terrault N. Ending vertical transmission of hepatitis B: the third trimester intervention. Hepatol Baltim Md. 2014;60(2):448-51. doi: https://doi.org/10.1002/hep.27145.

67. Ayres A, Yuen L, Jackson K, Manoharan S, Glass A, Maley M, et al. Short duration of lamivudine for the prevention of hepatitis $B$ virus transmission in pregnancy: lack of potency and selection of resistance mutations. J Viral Hepat. 2014;21(11):80917. doi: https://doi.org/10.1111/jvh.12212.

68. Chen JZ, Liao ZW, Huang FL, Su RK, Wang WB, Cheng $\mathrm{XY}$, et al. Efficacy and safety of tenofovir disoproxil fumarate in preventing vertical transmission of hepatitis B in pregnancies with high viral load. Sci Rep. 2017;7(1):4132. doi: https://doi.org/10.1038/s41598-017-04479-x. 
69. Jourdain G, Ngo-Giang-Huong N, Cressey T, Hua L, Harrison L, Tierney C, et al. Prevention of mother-to-child transmission of hepatitis B virus: a phase III, placebo-controlled, double-blind, randomized clinical trial to assess the efficacy and safety of a short course of tenofovir disoproxil fumarate in women with hepatitis B virus e-antigen. BMC Infect Dis. 2016;16:393. doi: https://doi.org/10.1186/ s12879-016-1734-5.

70. Hu Y, Chen J, Wen J, Xu C, Zhang S, Xu B, et al. Effect of elective cesarean section on the risk of mother-to-child transmission of hepatitis B virus. BMC Pregnancy Childbirth. 2013;13:119. doi: https://doi.org/10.1186/1471-2393-13-119.

71. Yang J, Zeng X, Men Y, Zhao L. Elective caesarean section versus vaginal delivery for preventing mother to child transmission of hepatitis B virus-A systematic review. Virol J. 2008;5:100. doi: https://doi.org/10.1186/1743422X-5-100.

72. Hill J, Sheffield J, Kim M, Alexander J, Sercely B, Wendel G. Risk of hepatitis B transmission in breast-fed infants of chronic hepatitis B carriers. Obstet Gynecol. 2002;99(6):1049-52. doi: https://doi.org/10.1097/00006250-200206000-00018.

73. Section on Breastfeeding. Breastfeeding and the use of human milk. Pediatrics. 2012;129(3):e827-41. doi: https:// doi.org/10.1542/peds.2011-3552.

74. Benaboud S, Pruvost A, Coffie P, Ekouévi D, Urien S, Arrivé E, et al. Concentrations of tenofovir and emtricitabine in breast milk of HIV-1-infected women in Abidjan, Cote d'Ivoire, in the ANRS 12109 TEmAA Study, Step 2. Antimicrob Agents Chemother. 2011;55(3):1315-7. doi: https://doi.org/10.1128/AAC.00514-10.

75. Brown R, Verna E, Pereira M, Tilson H, Aguilar C, Leu $\mathrm{CS}$, et al. Hepatitis B virus and human immunodeficiency virus drugs in pregnancy: findings from the Antiretroviral Pregnancy Registry. J Hepatol. 2012;57(5):953-9. doi: https://doi.org/10.1016/j.jhep.2012.06.031.

76. Ayoub W, Cohen E. Hepatitis B management in the pregnant patient: an update. J Clin Transl Hepatol. 2016;4(3):241-7. doi: https://doi.org/10.14218/JCTH.2016.00014.

77. European association for the study of the liver. Electronic address: easloffice@easloffice.eu, European Association for the Study of the Liver. EASL recommendations on treatment of hepatitis C 2018. J Hepatol. 2018;69(2):461511. doi: 10.1016/j.jhep.2018.03.026.

78. Page C, Hughes B, Rhee E, Kuller J. Hepatitis C in pregnancy: review of current knowledge and updated recommendations for management. Obstet Gynecol Surv. 2017;72(6):347-55. doi: https://doi.org/10.1097/OGX.0000000000000442.

79. Pott H, Theodoro M, de Almeida Vespoli J, Senise J, Castelo A. Mother-to-child transmission of hepatitis $\mathrm{C}$ virus. Eur J Obstet Gynecol Reprod Biol. 2018;224:125-30. doi: https://doi.org/10.1016/j.ejogrb.2018.03.034.

80. BenovaL,MohamoudY,Calvert C,Abu-RaddadL. Vertical transmission of hepatitis $C$ virus: systematic review and meta-analysis. Clin Infect Dis Off Publ Infect Dis Soc Am. 2014;59(6):765-73. doi: https://doi.org/10.1093/cid/ciu447.
81. Delotte J, Barjoan E, Berrébi A, Laffont C, Benos P, Pradier $\mathrm{C}$, et al. Obstetric management does not influence vertical transmission of HCV infection: results of the ALHICE group study. J Matern-Fetal Neonatal Med Off J Eur Assoc Perinat Med Fed Asia Ocean Perinat Soc Int Soc Perinat Obstet. 2014;27(7):664-70. doi: https://doi.org/10.3109/ 14767058.2013.829813.

82. Selvapatt N, Ward T, Bailey H, Bennett H, Thorne C, See LM, et al. Is antenatal screening for hepatitis $\mathrm{C}$ virus cost-effective? A decade's experience at a London centre. J Hepatol. 2015;63(4):797-804. doi: https://doi.org/10.1016/j. jhep.2015.05.015.

83. Diab-Elschahawi M, Dosch V, Honsig C, Jatzko B, Segagni $\mathrm{L}$, Assadian $\mathrm{O}$, et al. Evaluation of a universal vs a targeted hepatitis $\mathrm{C}$ virus screening strategy among pregnant women at the Vienna University Hospital. Am J Infect Control. 2013;41(5):459-60. doi: https://doi.org/10.1016/j. ajic.2012.06.003.

84. Bernstein H, Dunkelberg J, Leslie K. Hepatitis C in pregnancy in the era of direct-acting antiviral treatment: potential benefits of universal screening and antepartum therapy. Clin Obstet Gynecol. 2018;61(1):146-56. doi: https://doi. org/10.1097/GRF.0000000000000345.

85. Cottrell E, Chou R, Wasson N, Rahman B, Guise JM. Reducing risk for mother-to-infant transmission of hepatitis $C$ virus: $a$ systematic review for the U.S. Preventive Services Task Force. Ann Intern Med. 2013;158(2):109-13. doi: https://doi. org/10.7326/0003-4819-158-2-201301150-00575.

86. Valladares G, Chacaltana A, Sjogren MH. The management of HCV-infected pregnant women. Ann Hepatol. 2010;9:927. doi: https://doi.org/10.1016/S1665-2681(19)31731-4.

87. Barritt A, Jhaveri R. Treatment of hepatitis C during pregnancy-weighing the risks and benefits in contrast to HIV. Curr HIV/AIDS Rep. 2018;15(2):155-61. doi: https://doi. org/10.1007/s11904-018-0386-z.

88. Benjaminov F, Heathcote J. Liver disease in pregnancy. Am J Gastroenterol. 2004;99(12):2479-88. doi: 10.1111/j.15720241.2004.30231.x.

89. Giard JM, Terrault N. Women with cirrhosis. Gastroenterol Clin North Am. 2016;45(2):345-58. doi: https://doi. org/10.1016/j.gtc.2016.02.010.

90. Ramirez C, Doria C. Pregnancy after liver transplantation. Best Pract Res Clin Obstet Gynaecol. 2014;28(8):1137-45. doi: https://doi.org/10.1016/j.bpobgyn.2014.07.022.

91. Blume C, Pischke S, von Versen-Höynck F, Günter H, Gross M. Pregnancies in liver and kidney transplant recipients: a review of the current literature and recommendation. Best Pract Res Clin Obstet Gynaecol. 2014;28(8):1123-36. doi: https://doi.org/10.1016/j.bpobgyn.2014.07.021.

92. Akarsu M, Unek T, Avcu A, Ozbilgin M, Egeli T, Astarcioglu I. Evaluation of pregnancy outcomes after liver transplantation. Transplant Proc. 2016;48(10):3373-7. doi: https:// doi.org/10.1016/j.transproceed.2016.09.033. 